\title{
Bio-Material Analyses of Two Canola Cultivars Applied with Foliar Surfactant
}

\author{
Matthew Rhyan Miller ${ }^{1}$, Ramesh Ravella ${ }^{2}$, Muchha Reddy ${ }^{3}$, Abolghasem Shahbazi $^{4}$, \\ and Ron $\mathrm{Gehl}^{5}$ \\ 1,2,3,4 Department of Natural Resources and Environmental Design, School of Agriculture and \\ Environmental Sciences, North Carolina Agricultural and Technical State University, \\ Greensboro, NC, USA \\ ${ }^{5}$ Department of Soil Science, North Carolina State University, MHCREC, River, NC, USA
}

Correspondence should be addressed to: Matthew Rhyan Miller; mrmiller@aggies.ncat.edu

Received date: 19 September 2014; Accepted date: 6 March 2015; Published date: 22 August 2016

Academic Editor: Dennis Wiesenborn

Copyright (C) 2016. Matthew Rhyan Miller, Ramesh Ravella, Muchha Reddy, Abolghasem Shahbazi, and Ron Gehl. Distributed under Creative Commons CC-BY 4.0

\begin{abstract}
This study explores canola production in the south eastern United States in order to successfully adapt to the market demand for high valued oilseeds. Two primary objectives were established, determining yield response, and oil quality of harvested seed. Two canola cultivars were evaluated for production in a Piedmont soil (Mecklenburg Sandy Clay Loam) at NC A\&T State University research farm located in Greensboro, NC (Guilford County). The study was conducted using a split-plot design with the main plot factor cultivar (Virginia and DKW 46-15), and subplot factor fertilizer rate: $\left(\mathrm{N}-\mathrm{P}_{2} \mathrm{O}_{5}-\mathrm{K}_{2} \mathrm{O}\right)$ in $(\mathrm{kg} / \mathrm{ha})$ 0-0-0 (T1), 70-28-84 + Soysoap (T2), 14056-168 (T3) and 140-56-168+Soysoap (T4). Canola oil was extracted using a soxhlet apparatus. For both seed and oil yield response, the effects of fertilizer treatment and cultivar were significant influences. Seed and oil yield response was statistically higher for DKW 46-15 compared to the Virginia cultivar. Application of treatment T4 will maximize oil and seed yield compared to treatments T2 \& T1 fertilizer treatments. Higher erucic fatty acid concentrations were found in oil originating from Virginia seeds compared to DKW 46-15. Based on yield response and fatty acid composition, DKW 46-15 might better serve the bio-material feedstock supply chain compared to the Virginia cultivar when produced in the piedmont region of North Carolina.
\end{abstract}

Keywords: Fatty Acids, Canola, Bio-Fuel, Piedmont.

Cite this Article as: Matthew Rhyan Miller, Ramesh Ravella, Muchha Reddy, Abolghasem Shahbazi, and Ron Gehl (2016)," Bio-Material Analyses of Two Canola Cultivars Applied with Foliar Surfactant " International Journal of Renewable Energy and Biofuels, Vol. 2016 (2016), Article ID 658623, DOI: 10.5171/2016.658623 


\section{Introduction}

Canola, palm, soybeans, and sunflower seeds contribute up to $79 \%$ of the global vegetable oil on the market (Dyer et al. 2008). Due to both the increasing demand for food consumption in conjunction with the increased interest in bio-fuel feedstock's, consumption of vegetable oil has increased $50 \%$ over the past decade (Lu et al. 2011). Increased market demand coupled with consequent rise in oil prices are forcing industries that rely on natural fats and oils for bio-based formulations i.e. bio-fuel, surfactants, and lubricants, to seek new feedstock's for products and applications. One oil source gaining interest is canola (Meier et al. 2007). The potential of canola as a bio-oil source has been well demonstrated (Sensoz, Angin, Yorgun 2000; Yu et al. 2010; Suqi et al. 2014).

Our goal was to ease the transition of canola production into the southeastern US. To accomplish this we need to find the highest yielding varieties suitable to our climate, as well as determine optimum fertilizer application rate. We evaluated two winter canola varieties to determine their yield potential. Producers not only rely on high yielding varieties, but also on nutrient management practice systems to supply necessary nutrition to crops. Efficient nutrient management practices include sufficient and timely introduction of needed nutrients, as well as minimal reliance on excess nutrient supplementation. Previous research has shown that when nitrogen $(\mathrm{N})$ fertilizer application to canola is increased, a noticeable reduction in oil content is observed, while at the same time seed yield, energy production, $\mathrm{CO}_{2}$ storage, and crude protein content are all increased (Rathke, Christen \& Diepenbrock 2005). Therefore to maintain a profitable oilseed crop, producers need to manage optimal nitrogen application to produce high oil content. We investigated the effect of 3 different (N-P-K) applications and their differential effect on yield response. In conjunction with the rate of application, we investigated foliar Soysoap ${ }^{\mathrm{TM}}$ application during a critical growth time (flowering) for canola. Soysoap is a bio-based surfactant currently available on the market for multiple agricultural applications that has the potential for reducing nitrogen supplementation while increasing efficiency of nutrient uptake. Our goal was to achieve increased seed and oil yields while simultaneously reducing fertilizer inputs.

Canola oil quality is an important aspect that needs to be addressed in order to determine the optimum nutrient management practice to achieve the highest value. For this reason, this study examined not only the growth profile resulting from the growth system but the production value of the canola oil. The most important quality parameter for lipid production in oilseed crops is determined by its fatty acid composition. Oil quality is determined by its oleic, linoleic, and erucic acid contents (Aslam et al. 2009; Schierholt \& Becker 2011; Rad \& Zandi 2012). The concentration of these fatty acids is affected by genomic differences between varieties and environmental influences. Environmental conditions (heat and salinity) as well as management practices (planting date and fertilizer application) affect fatty acid metabolism. Fatty acid profiles are susceptible to seasonal variation due to climatic influences such as temperature. Temperature fluctuations during crop production can delay seed maturation altering fatty acid profiles (Deng \& Scarth 1998). Canola is most vulnerable to fatty acid profile changes during flowering (2-5 week duration). During this period, the seed's cotyledons experience changes in fatty acid composition, accompanied by rapid oil accumulation (Aksouh-Harradj, Campbell \& Mailer 2006). Nutrient supply also has a significant influence on biochemical reactions that affect fatty acid development (DeBonte et al. 2012). Researchers have noted that increasing $\mathrm{N}$ fertilization from 100 $\mathrm{kg} / \mathrm{ha}$ to $150 \mathrm{~kg} / \mathrm{ha}$ increased palmitic, stearic, oleic, linoleic, linolenic, arachidic, eicosenoic, behenic, erucic and nervonic fatty acid concentrations (Zheljazkov et al. 2012).

Matthew Rhyan Miller, Ramesh Ravella, Muchha Reddy, Abolghasem Shahbazi, and Ron Gehl (2016), International Journal of Renewable Energy and Biofuels, DOI: 10.5171/2016.658623 


\section{Objectives}

Primary: Determining the effectiveness of cultivar selection, and fertilizer treatment application on yield response.

Secondary: Investigating fatty acid profiles of individual treatments partitioned by the effects of cultivar selection, and fertilizer treatment application.

\section{Methodology}

\section{Experimental Design}

The experiment was conducted at North Carolina Agricultural and Technical State University Research Farm which is located $223 \mathrm{~m}$ above the sea level. The current climate hardiness zone is classified as zone 7A. The experiment was conducted on a soil type classified as a Mecklenburg Sandy Clay Loam (Taxonomic class: Fine, mixed, active, Thermic Ultic Hapludalfs). The soil is well drained with $6-10 \%$ slopes, and moderately eroded. The experimental design was a $2 \mathrm{X} 4$ split plot randomized complete block, with 2 cultivars (Virginia and DKW 46-15) as main plots, and fertilizer rates (4) as sub plot, in 4 replications. Fertilizer rates included: (T4) 140-56-168 (N-P-K) $\mathrm{kg} / \mathrm{ha} \quad(100 \%$ dose fertilizer (DF)+Soysoap), (T3) 140-56-168 $(\mathrm{N}-\mathrm{P}-\mathrm{K}) \mathrm{kg} / \mathrm{ha}(100 \% \mathrm{DF}),(\mathrm{T} 2)$ 70-28-84 $\mathrm{kg} / \mathrm{ha}(\mathrm{N}-\mathrm{P}-\mathrm{K})+$ Soysoap (50\% DF+Soysoap) and (T1) $0-0-0 \mathrm{~kg} / \mathrm{ha}$ (N-P-K) (control). Each subplot was $6 \mathrm{~m} \times 10 \mathrm{~m}$. Canola was planted on October $1^{\text {st }}(2010)$ and October $7^{\text {th }}$ (2011). Canola was manually harvested on May $21^{\text {st }}$ (2011), and May 31st (2012).

\section{Oil extraction}

Solvent extraction was performed using a Soxhlet apparatus using a Pyrex® Allihn condenser with a $500 \mathrm{ml}$ round bottom flask heated with analytical grade hexane. Lipid extraction was completed following a modification of AOAC Official Method;948.22 (Venkatachalam 2006). Forty grams of the seed was pulverized using a coffee grinder for 15 seconds. Seed cake was then placed into a cellulose extraction thimble $(43 \mathrm{~mm} \mathrm{x}$ $123 \mathrm{~mm}$ ) and extracted with $400 \mathrm{ml}$ of hexane which was poured into the still pot of the soxhlet apparatus. The temperature was brought to $69^{\circ} \mathrm{C}$ (boiling point of hexane) and the extraction tube was inserted along with the condenser tube. The thimble was then placed into the condenser tube. Reflux took place for 6 hours. The still pot was removed and the contents poured into an uncapped $500 \mathrm{ml}$ beaker and the hexane solvent was allowed to evaporate by placing the beaker in a fume hood at ambient temperature. Residual oil samples were then weighed and lipid content determined by AOAC 920.39. Number of extractions were based on the number of plots that were separated by both fertilizer treatment and variety $(\mathrm{N}=32)$. Each plot was extracted in triplicate. Oil percentage was calculated by placing the oil extracted during chemo-solvent extraction into an uncapped $500 \mathrm{ml}$ beaker which was then placed in a Fischer scientific isotemp oven for 24 hours at $80 \mathrm{oC}$. After drying was complete, oil weight was determined.

\section{Fatty Acid Analysis}

Fatty acid analyses were performed using oil samples collected from the extraction process using procedures detailed by Kaluzny et al. (1985). Samples from oil extraction were weighed (between 0.23$0.27 \mathrm{~g}$ ) and then placed into a $15 \mathrm{ml}$ vial. $10 \mathrm{ml}$ of a 2:1 chloroform: methanol mixture was added to each sample and then vortexed for 30 seconds and allowed to settle for 5 minutes. The samples were then centrifuged at $15^{\circ} \mathrm{C}$ for 10 minutes at $3,000 \mathrm{rpm}$. A $3 \mathrm{ml}$ portion from the bottom layer of the resulting sample mixture from these samples was extracted and applied to a preconditioned supelco supelclean LC- $\mathrm{NH}_{2}$ SPE cartridge. The samples were eluted with $6 \mathrm{ml}$ hexane followed by $3 \mathrm{ml}$ of a 2:1 chloroform: methanol mixture and then treated with $3 \mathrm{ml}$ of a 2:1 chloroform/isopropanol mixture to the cartridge to remove the neutral lipids. All fractions containing pure solvent were discarded. The free fatty acids were then eluted off of the LC- $\mathrm{NH}_{2}$ column using $6 \mathrm{ml}$ of

Matthew Rhyan Miller, Ramesh Ravella, Muchha Reddy, Abolghasem Shahbazi, and Ron Gehl (2016), International Journal of Renewable Energy and Biofuels, DOI: 10.5171/2016.658623 
$2 \%$ acetic acid in diethyl ether and collected in a $10 \mathrm{ml}$ sample vial. These prepared samples were then analyzed on Gas Chromatography Thermo Fisher Trace GC equipped with Triplus Autosampler using nukol megabore column.

\section{Statistical Software and Analysis}

Data collected from each plot $(\mathrm{N}=32)$ on seed and oil solvent yield were analysed using a PROC GLM procedure of SAS (version 9.2; SAS Institute Inc., Cary, NC) using a split plot design. Oil quality was accessed through total fatty acid analysis that evaluated 5 important fatty acid concentrations related to canola production (Oleic, Linoleic, Linolenic, Palmitic, and Erucic). All analyses conducted used Duncan's multiple range test for post hoc analysis $(\alpha=0.05)$.

\section{Results}

Canola yield (seed and oil) responses are dominated by two primary factors; genomics and nutrient management practices. Our study concluded that seed and solvent extracted oil yields (kg/ha) were significantly influenced by cultivar selection and fertilizer treatment application (Table 1).

\section{Table 1: $P$-Values observed during individual split-plot analyses}

\begin{tabular}{|l|c|c|}
\hline Effect & Seed Yield & Solvent 0il Yield \\
\hline Treatment & 0.001 & 0.001 \\
\hline Cultivar & 0.001 & 0.01 \\
\hline Interaction & 0.13 & 0.49 \\
\hline
\end{tabular}

$\dagger=$ Each column represents individual analyses of seed and oil yield response due to fertilizer treatment applied and cultivar selected. Significance was determined at $(\alpha=0.05 \%)$.

Cultivar selection was a pivotal factor affecting yield response for both observed seed and oil yields. DKW 46-15 statistically produced superior yields compared to the Virginia cultivar (Table 2). Fertilizer treatment was also a significant influence which affected yield response (Table 1).

Table 2: Cultivar Effect on Seed and Oil Yields (kg/ha)

\begin{tabular}{|l|l|l|}
\hline Variety & Seed Yield & Solvent Oil \\
\hline DKW & $684.89 \pm 252.90_{\mathrm{A}}$ & $259.53 \pm 78.88_{\mathrm{A}}$ \\
\hline Virginia & $494.51 \pm 229.84_{\mathrm{B}}$ & $179.47 \pm 75.26_{\mathrm{B}}$ \\
\hline
\end{tabular}

$\dagger=$ Each column represents individual analyses of cultivar effect on seed and oil yield response. Mean followed by different letters in each column are significantly different (Duncan multiple range test at $\alpha=0.05 \%$ ).

The highest Duncan grouping observed in both seed and oil yield response was obtained with the application of treatment T4 (Table 3). An interesting trend was observed between similar yield responses between treatments T2, and T3 (Table 3). Treatment T2 was applied with half the fertilizer (N-P-K) as treatment T3 however, T2 received soysoap application (Table 3). 
Table 3: Fertilizer Treatment Effect on Seed and Oil Yields (kg/ha)

\begin{tabular}{|c|c|c|}
\hline Treatment & Seed & Solvent Oil \\
\hline $\mathrm{T} 1$ & $320.89 \pm 168.62_{\mathrm{C}}$ & $123.01 \pm 56.41_{\mathrm{C}}$ \\
\hline $\mathrm{T} 2$ & $592.72 \pm 175.46_{\mathrm{B}}$ & $205.96 \pm 73.10_{\mathrm{B}}$ \\
\hline $\mathrm{T} 3$ & $610.10 \pm 123.57_{\mathrm{BA}}$ & $216.45 \pm 48.42_{\mathrm{BA}}$ \\
\hline $\mathrm{T} 4$ & $758.29 \pm 337.57_{\mathrm{A}}$ & $287.16 \pm 90.04_{\mathrm{A}}$ \\
\hline
\end{tabular}

$\dagger=$ Each column represents individual analyses of fertilizer treatment effect on seed and oil yield response. Mean followed by different letters in each column are significantly different (Duncan multiple range test at $\alpha=0.05 \%$ ).

Both seed and oil yield shared a similar response in which the control or nil-applied fertilizer treatment produced significantly lower yields compared to the other treatments evaluated.

\section{Fatty Acid Profile}

After yield response was determined, we evaluated quality characteristics of solvent extracted oil. The effect of fertilizer treatment and cultivar selected on fatty acid profile was the focus of the analyses (Table 4). Genetic influences were shown to be the strongest influence on fatty acid profiles between the two varieties (Table 4). The Virginia cultivar displayed significantly higher erucic fatty acid concentrations compared to DKW 46-15 (Table 5). We found that the rate of fertilizer treatment applied had little effect on fatty acid profiles between the two canola cultivars studied (Table 4).

Table 4: $P$-Values observed during individual split-plot analyses

\begin{tabular}{|l|c|c|c|c|c|}
\hline Effect & $\mathbf{1 6 : 0 0}$ & $\mathbf{1 8 : 0 1}$ & $\mathbf{1 8 : 0 2}$ & $\mathbf{1 8 : 0 3}$ & $\mathbf{2 2 : 0 1}$ \\
\hline Treatment & 0.48 & 0.63 & 0.13 & 0.90 & 0.07 \\
\hline Cultivar & 0.30 & 0.89 & 0.78 & 0.63 & 0.01 \\
\hline Interaction & 0.55 & 0.43 & 0.74 & 0.40 & 0.94 \\
\hline
\end{tabular}

$\dagger=(16: 0)$ Palmitic FA, (18:1) Oleic FA, (18:2) Linoleic FA, (18:3) Linolenic FA, (22:1) Erucic FA. Significance was determined at $(\alpha=0.05 \%)$.

Table 5: Cultivar effect on fatty acid analyses

\begin{tabular}{|l|c|c|c|c|c|}
\hline Effect & $\mathbf{1 6 : 0 0}$ & $\mathbf{1 8 : 0 1}$ & $\mathbf{1 8 : 0 2}$ & $\mathbf{1 8 : 0 3}$ & $\mathbf{2 2 : 0 1}$ \\
\hline DKW 46-15 & 3.44 & 71.93 & 15.09 & 6.15 & $0.20_{\mathrm{B}}$ \\
\hline Virginia & 3.26 & 71.4 & 15.17 & 6.32 & $0.52_{\mathrm{A}}$ \\
\hline
\end{tabular}

$\dagger=$ Mean followed by different letters in each column are significantly different (Duncan multiple range test at $\alpha=0.05 \%),(16: 0)$ Palmitic FA, (18:1) Oleic FA, (18:2) Linoleic FA, (18:3) Linolenic FA, (22:1) Erucic FA. 


\section{Discussion}

\section{Yield Response}

Bio-fuel refineries are in an early developmental stage in North Carolina. For the stabilization of market demand to occur, a reliable feedstock needs to be made readily available. Therefore, we established a cultivar and nutrient management field trail to enhance canola production in the south eastern US. Seed and oil yield are the two most important aspects of canola production. Seed quantity produced is directly affected by genomic influences such as cultivar selection and nutrient management practices (rate of fertilizer applied). Our study evaluated two different winter canola cultivars; Virginia and DKW 46-15. We found that DKW 46-15 produced higher seed and oil yields compared to the Virginia variety.

Another consideration affecting crop productivity and operation cost is nutrient application. We evaluated 3 different fertilizer rates to see the response from (N-P$\mathrm{K})$ application, as well as the effect of soysoap application on yield. Surfactants such as Soysoap may potentially affect absorption/desorption processes which affect nutrient and water absorption mechanisms. Treatments T3 -without soysoap and T4 -with soysoap produced similar yields between the cultivars tested. However, the most dramatic response observed occurred when plots were applied with treatment $\mathrm{T} 4$ in comparison to $\mathrm{T} 2$, or T1. Underlying mechanisms such as increased water and nutrient delivery may be the cause of increased yield response associated with soysoap application. However, to further confirm this on a physiological level goes beyond the scope of the current field trial evaluation.

\section{Biofuel Feedstock Quality}

Producers have several factors which influence their options for oil extraction. Solvent extraction is more efficient in terms of quantity of oil produced compared to mechanical pressing. However, negative drawbacks using solvent extraction consist of longer and more expensive processing, production of hazardous waste, and alteration of end quality output (Buenrostro \& López-Munguia 1986; Wei et al. 2012). Fatty acid composition impacts several characteristics of biodiesel quality such as: flashpoint, viscosity, cetane number, cloud point, pour point, calorific value, acid value, ash content, and cold flow properties. Two primary areas of interest for bio-fuel feedstock production involve combustion and storage characteristics. We evaluated fatty acid profiles by cultivar selection and fertilizer treatment effects.

Over time plant breeders developed Brassica napus to contain lower amounts of erucic acid due to detrimental effects when used as food or fodder; however, erucic fatty acid has important industrial applications, therefore evaluating cultivar performance can help producers select appropriate end use varieties (Nosenko, Hutsalo et al. 2013). Erucic fatty concentrations were consistently higher from oil originating from the Virginia cultivar compared to DKW 46-15. Oil containing increased saturation of erucic fatty acids will require additional processing for biodiesel production which will increase production cost. Having higher erucic acid concentrations could be adventitious depending on the oil end use, high fatty acid concentrations may be favourable; oleic and erucic fatty acids have been previously sought for the utilization in bio-based polyesters (Yang et al. 2009).

\section{Conclusion}

Producing high value fatty acids through oilseed crops can help supplement and replace the use of non-sustainable petroleum and oceanic resources (Cahoon et al. 2007). As we explore oil seed feedstocks for bio-fuel production as well as other manufacturing purposes determining fatty acid composition, management practices, and/or choice of cultivars to plant that optimize canola production will help producers and suppliers 
better meet market demands. We observed greater yields (seed and oil) with DKW 46-15 compared to the Virginia cultivar. Fertilizer treatment trends were noted in yield response with soysoap application; treatments T2 -with soysoap (reduced fertilizer rate), and T3 -without soysoap (increased fertilizer rate) produced similar yields, and a higher yield response was observed for treatment T4 compared to T2, and T1. The exact role of soysoap in improving the yield could not be determined within the scope of this study. Future studies should be directed at smaller (N-P-K) application rates in conjunction with soysoap

\section{References}

1. Aksouh-Harradj, N. M., Campbell, L. C., and Mailer, R. J. (2006). "Canola response to high and moderately high temperature stresses during seed maturation." Canadian Journal of Plant Science, 86(4), 967-980.

2. Aslam, M. N., Nelson, M. N., Kailis, S. G., Bayliss, K. L., Speijers, J., and Cowling, W. A. (2009). "Canola oil increases in polyunsaturated fatty acids and decreases in oleic acid in drought-stressed mediterranean-type environments." Plant Breeding, 128 (4) 348-355

3. Buenrostro, M. and A. López-Munguia (1986). "Enzymatic extraction of avocado oil." Biotechnology letters

4. 8 (7) 505-506.

5. Cahoon, E. B., Shockey, J. M., Dietrich, C. R., Gidda, S. K., Mullen, R. T., and Dyer, J. M. (2007). "Engineering oilseeds for sustainable production of industrial and nutritional feedstocks: solving bottlenecks in fatty acid flux." Current opinion in plant biology, 10 (3) 236-244.

6. DeBonte, L., Iassonova, D., Liu, L., and Loh, W. (2012). "Commercialization of high oleic canola oils." Lipid Technology, 24 (8) 175-177.

7. Deng, X., and Scarth, R. (1998). "Temperature effects on fatty acid application. Oil quality was primarily affected by genomic influences due to cultivar selection. Erucic fatty acid concentrations were statistically higher regardless of the extraction method used.

\section{Acknowledgment}

Funding was provided by Evans Allen. The review of the manuscript by Dr. J. Emrani and Dr. K. Gruber is appreciated. This work could not have been completed without the assistance of John Carver and Bryce Holmes.

composition during development of lowlinolenic oilseed rape (Brassica napus L.)." Journal of the American Oil Chemists Society, 75 (7) 759-766. doi: 10.1007/s11746-9980223-4

8. Dyer, J. M., Stymne, S., Green, A. G., and Carlsson, A. S. (2008). "High-value oils from plants." Plant Journal, 54 (4) 640-655. doi:10.1111/j.1365-313X.2008.03430.x

9. Kaluzny, M. A., Duncan, L. A., Merritt, M. V., and Epps, D. E. (1985). "Rapid separation of lipid classes in high yield and purity using bonded phase columns." Journal of Lipid Research, 26 (1) 135-140.

10.Lu, C., Napier, J. A., Clemente, T. E., and Cahoon, E. B. (2011). "New frontiers in oilseed biotechnology: meeting the global demand for vegetable oils for food, feed, biofuel, and industrial applications." Current opinion in biotechnology, 22 (2) 252-259.

11.Meier, M. A., Metzger, J. O., \& Schubert, U. S. (2007). "Plant oil renewable resources as green alternatives in polymer science." Chemical Society Reviews, 36 (11) 1788-1802.

12.Nosenko, T., Hutsalo, I., Nosenko, V., Levchuk, I., \& Litvynchuk, S. (2013). "Analysis of near infrared reflectance spectrum of rape seed with different content of erucic acid". Ukrainian journal of food science, 1 (1) 94-99.

13.Rad, S., and Zandi, P. (2012). "Comparison of winter and spring rapeseed cultivars

Matthew Rhyan Miller, Ramesh Ravella, Muchha Reddy, Abolghasem Shahbazi, and Ron Gehl (2016), International Journal of Renewable Energy and Biofuels, DOI: 10.5171/2016.658623 
considering their oil content and fatty acid composition." American-Eurasian J. Agric. and Environ. Sci. 12 (6) 775-780, doi: 10.5829/idosi.aejaes.2012.12.06.1750

14. Rathke, G. W., Christen, O., and Diepenbrock, W. (2005). "Effects of nitrogen source and rate on productivity and quality of winter oilseed rape (Brassica napus L.) grown in different crop rotations." Field Crops Research, 94 (2-3) 103-113. doi: 10.1016/j.fcr.2004.11.01

15.Sas Institute. (2008). SAS software, version 9.2 .

16.Schierholt, A., and Becker, H. C. (2011). "Influence of oleic acid content on yield in winter oilseed rape." Crop Science, 51 (5) 1973-1979.

17.Sensoz, S., Angın, D., \& Yorgun, S. (2000). "Influence of particle size on the pyrolysis of rapeseed (Brassica napus L.): fuel properties of bio-oil." Biomass and Bioenergy, 19 (4) 271-279.

18.Suqi, L., Caceres, L., Schieck, K., Booker, C. J., McGarvey, B. M., Yeung, K. \& Scott, I. M. (2014). "Insecticidal Activity of Bio-oil from the Pyrolysis of Straw from Brassica spp." Journal of agricultural and food chemistry, 62 (16) 3610-3618
19.Venkatachalam, M. and S. K. Sathe (2006). "Chemical Composition of Selected Edible Nut Seeds." Journal of Agricultural and Food Chemistry 54 (13) 4705-4714.

20.Wei, F., Yang, M., Zhou, Q., Zheng, C., Peng, J. H., Liu, C. S., and Chen, H. (2012). "Varietal and processing effects on the volatile profile of rapeseed oils." LWT-Food Science and Technology, 48 (2) 323-329.

21.Yang, Y., Lu, W., Zhang, X., Xie, W., Cai, M., and Gross, R. A. (2009). "Two-step biocatalytic route to biobased functional polyesters from $\omega$-carboxy fatty acids and diols." Biomacromolecules, 11 (1) 259-268.

22.Yu, J. T., Dehkhoda, A. M., \& Ellis, N. (2010). "Development of biochar-based catalyst for transesterification of canola oil." Energy \& Fuels, 25 (1) 337-344.

23.Zheljazkov, V. D., Vick, B., Ebelhar, M. W., Buehring, N., and Astatkie, T. (2012). "Nitrogen applications modify seed and oil yields and fatty acid composition of winter mustard." Industrial Crops and Products, 36 (1) 28-32. 